\title{
Vero cells gain renal tubule markers in low-calcium and magnesium chemically defined media
}

\author{
Megan Logan ${ }^{1}$, Karsten Rinas ${ }^{1}$, Brendan McConkey ${ }^{1}$, and Marc Aucoin ${ }^{1}$ \\ ${ }^{1}$ University of Waterloo
}

June 14, 2021

\begin{abstract}
In this study, a chemically defined, animal component-free media was developed to promote Vero growth in suspension. Key media compounds were screened using Plackett-Burman styled experiments to create a media formulation to support suspension growth. Vero cells remained viable in suspension, but their growth rate was extremely low, conversely, other cell types such as CHO-K1, MDCK and HEK293T were able to grow in single cell suspension in the same media. To investigate the slow growth of Vero cells, RNA-Seq analysis was conducted. Vero cells were cultured in three different conditions: adherently in serum-containing medium, adherently in in-house medium, and in suspension in low calcium and magnesium in-house medium. This study illustrates that adherent cells maintain similar gene expression, while the suspension phenotype tends to overexpress genes related to renal tubules.
\end{abstract}

\section{Hosted file}

Logan et al Submitted Manuscript May 202176_Karsten_edits.docx available at https: //authorea.com/users/419707/articles/526116-vero-cells-gain-renal-tubule-markers-inlow-calcium-and-magnesium-chemically-defined-media
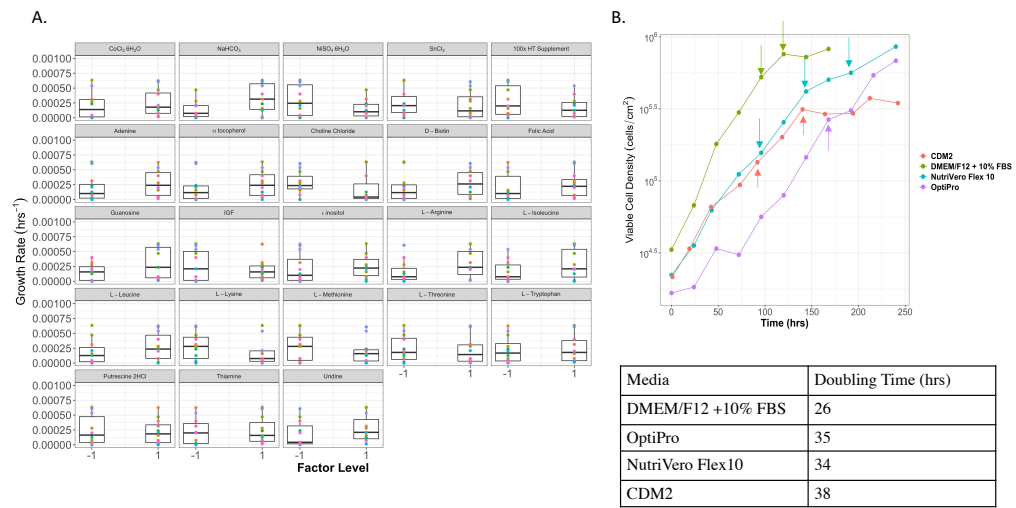
A.

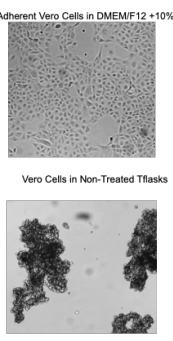

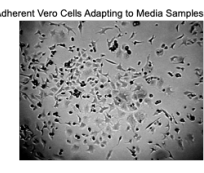

Vero Colls in formula 17 with Shaking

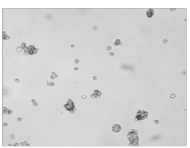

B.

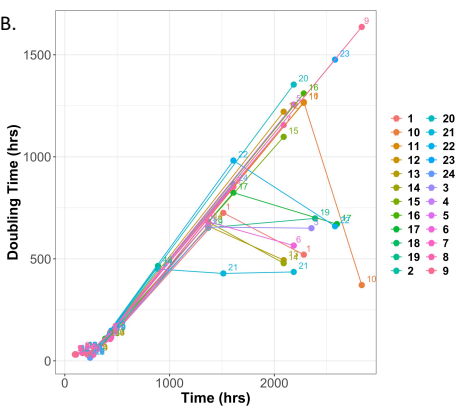

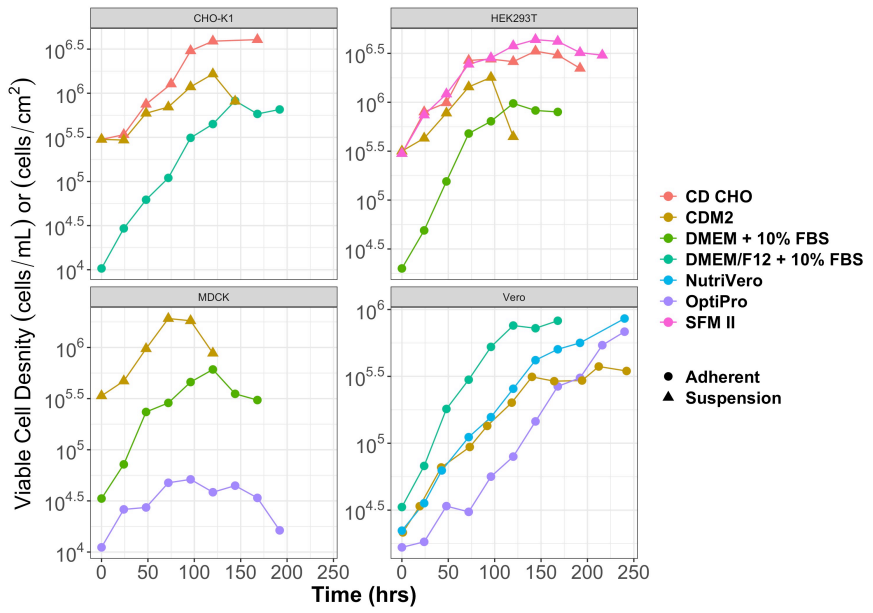



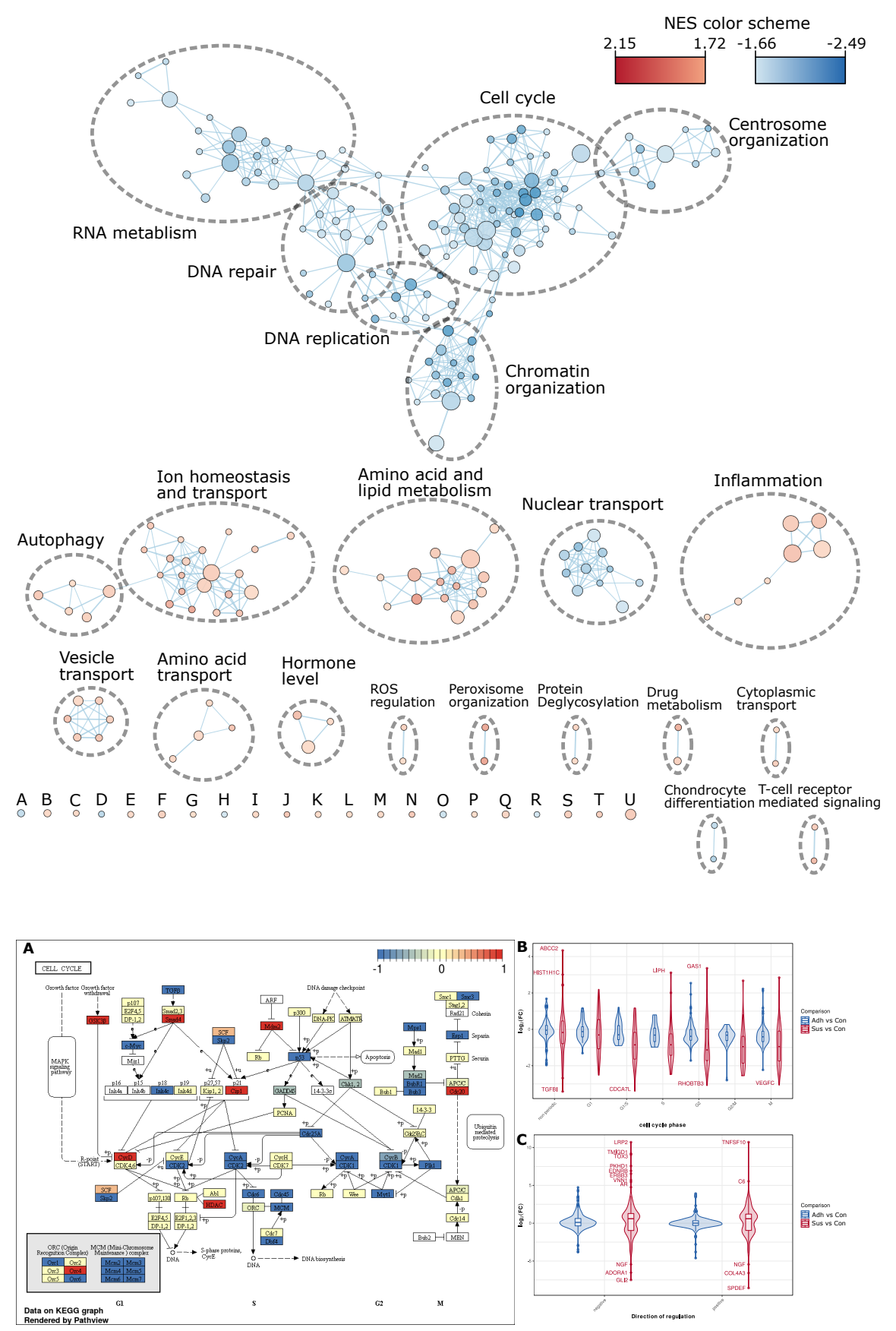
A

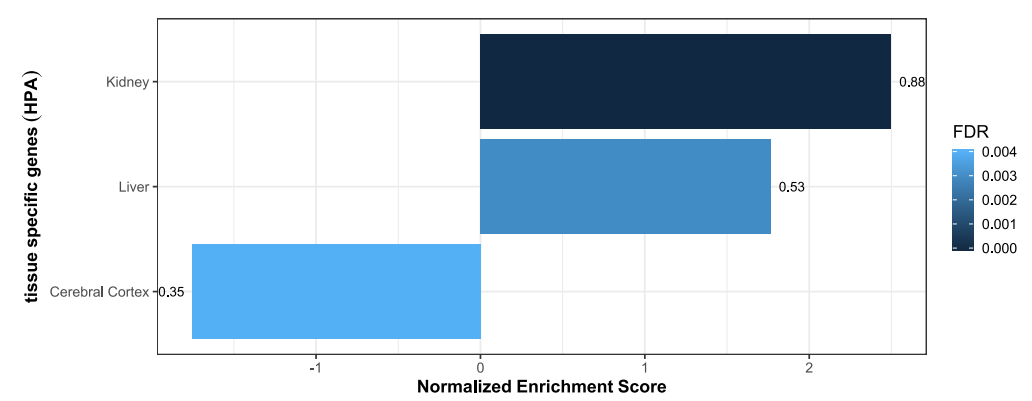

B

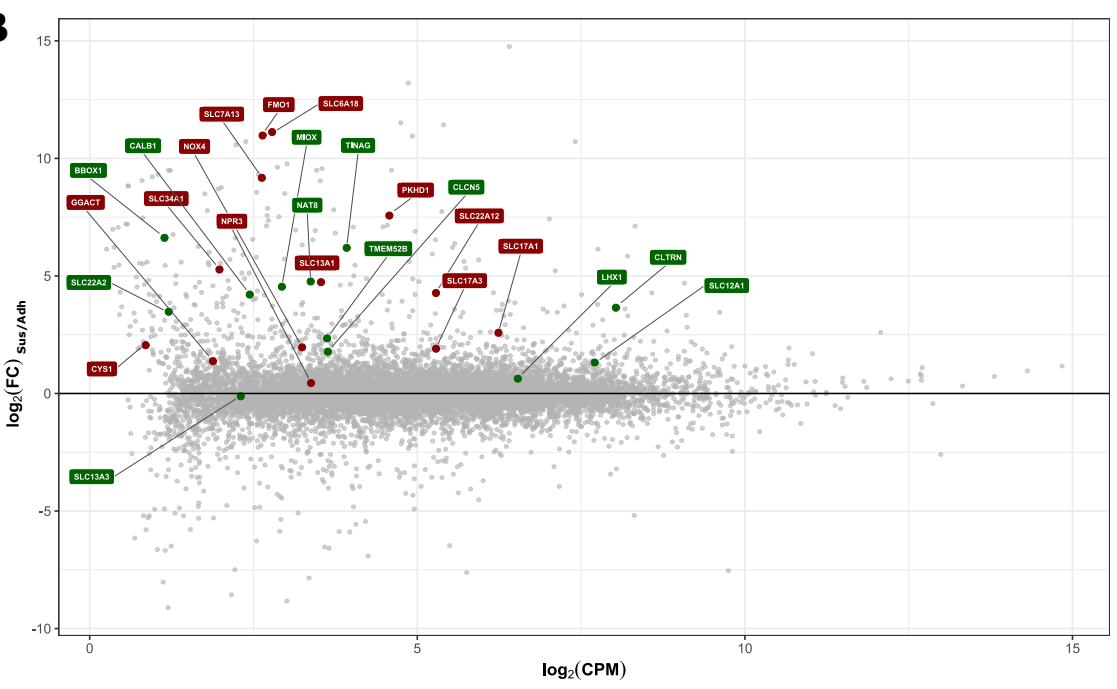

\section{Hosted file}

Figure_7_corrected.pdf available at https://authorea.com/users/419707/articles/526116-verocells-gain-renal-tubule-markers-in-low-calcium-and-magnesium-chemically-defined-media
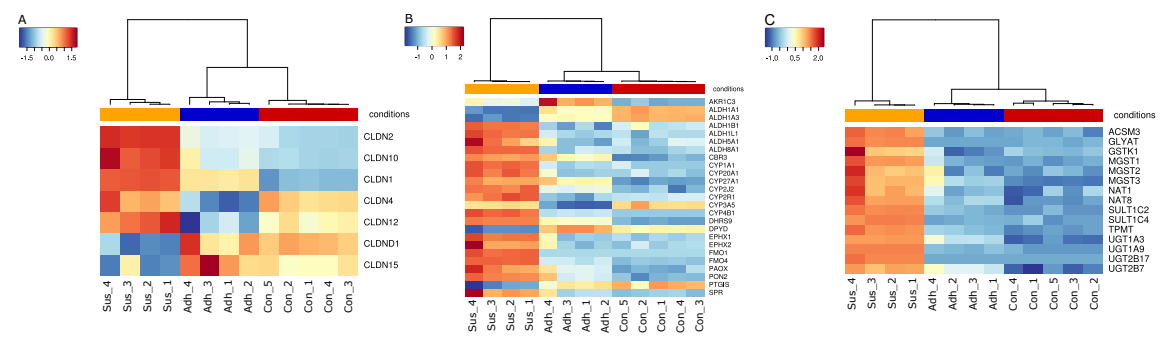

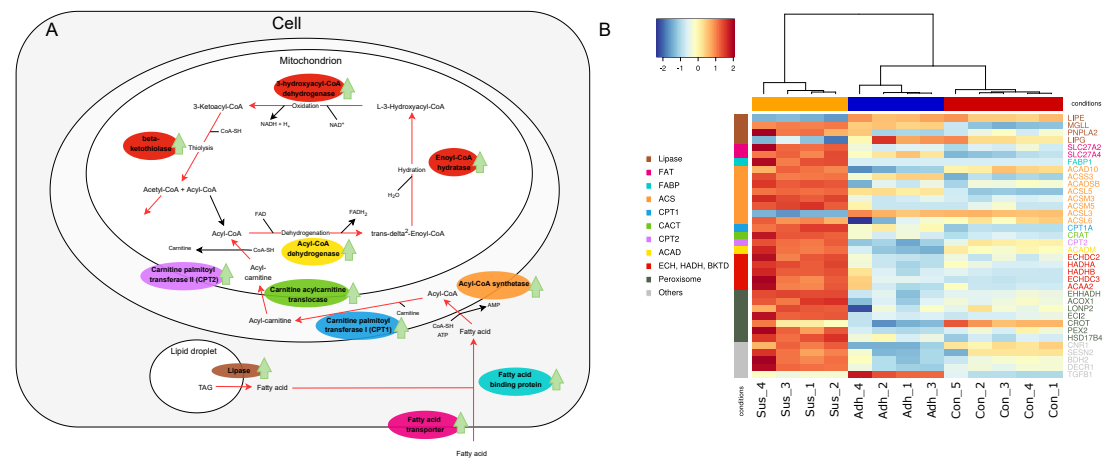